\title{
DOS CÂNONES AO MANGÁ: INDICAÇÕES DE LEITURA DOS ESTUDANTES DE LETRAS E PEDAGOGIA
}

\section{FROM THE CANONS TO MANGA: READING RECOMMENDATIONS FROM LITERATURE AND PEDAGOGY UNDERGRADUATE STUDENTS}

\begin{abstract}
Arlene Batista da SILVA*
Resumo: Este artigo constitui parte integrante do projeto "Leitura nas licenciaturas: espaços, materialidades e contextos na formação docente". Aborda as indicações de leituras literárias feitas por graduandos iniciantes dos cursos de Letras e Pedagogia, sujeitos de uma pesquisa interdisciplinar financiada pelo Programa de Cooperação Acadêmica (PROCAD/CAPES), desenvolvida de forma cooperativa entre quatro universidades de diferentes regiões do país. Tem como objetivo principal mapear experiências de leitura literária dos graduandos, os gostos, as condutas, as concepções de leitura literária e de literatura, bem como as forças que convergem na construção dessas representações. Tomou como objeto de análise duas questões abertas que solicitaram a indicação de um livro que tenha interessado/sensibilizado os estudantes, acrescidas de justificativa. Os resultados da pesquisa evidenciam a influência de diferentes campos na formação literária desses sujeitos. Os comentários dos leitores sobre as literaturas (clássicas e de massa) indiciam que a leitura literária é vista como forma de entretenimento, prazer, consolo, apropriação de conhecimentos, reflexão sobre a existência humana. Suas leituras, que se limitam ao seu repertório cultural e às relações subjetivas que estes estabelecem no contato com a obra, nem por isso devem ser desqualificadas, desrespeitadas, pois essas práticas somarse-ão a outras que serão apropriadas em sua formação acadêmica, ampliando sua biblioteca interior.
\end{abstract}

Palavras-chave: Leitura literária. Prazer estético. Práticas de leitura.

\begin{abstract}
This paper is part of the project "Reading in undergraduate courses: spaces, materialities and contexts in teacher education". It analyses the recommendations of literary readings made by Literature and Pedagogy undergraduate students, who were participants of an interdisciplinary research funded by Academic Cooperation Program (PROCAD/ CAPES), developed in four universities from different regions of Brazil. Its main objective is to map undergraduate students' literary reading experiences, preferences, behaviors, concepts of literary reading and literature, as well as the forces that converge in the construction of these representations. The study was based on the answers to two open questions, which demanded participants to recommend a book that had interested/touched them, followed by a justification. Analyses show the influence of different fields in the literary formation of these subjects. Readers' comments on literatures (classical and mass) indicate that literary reading is seen as a form of entertainment, pleasure, comfort, appropriation of knowledge, and reflection on human existence. Their readings, are limited to their cultural repertoire and the subjective relationships that they establish in contact with the work, should not be disqualified, disrespected, because these practices are added to others that should be appropriated in their academic education, expanding their personal library.
\end{abstract}

Key Words: Literary Reading. Aesthetic pleasure. Reading practices.

\footnotetext{
* Professora da Universidade Federal do Espírito Santo (UFES). Doutorado em Letras pela UFES. E-mail: arleneincrivel@gmail.com.
} 


\section{Considerações iniciais}

Este estudo constitui parte integrante do projeto "Leitura nas licenciaturas: espaços, materialidades e contextos na formação docente", desenvolvido de forma cooperativa entre quatro instituições de diferentes regiões do país, a saber: o Programa de Pós-Graduação em Educação do campus Marília da Universidade Estadual Paulista Júlio de Mesquita Filho, o Programa de Pós-Graduação em Educação do campus Presidente Prudente da mesma instituição, o Programa de Pós-Graduação em Letras e o Programa de Pós-Graduação da Universidade Federal do Espírito Santo e o Programa de Pós-Graduação em Letras da Universidade de Passo Fundo.

O projeto coletivo busca responder questões relacionadas à leitura na formação dos licencia(n)dos em Letras-Português e em Pedagogia. O estudo sobre a temática da leitura tornase urgente nesse contexto, pois os graduandos, ao se formarem, atuarão diretamente no ensino da leitura e da escrita enquanto práticas sociais a serem apropriadas pelos alunos da Educação Básica, bem como na construção do gosto pela literatura como experiência estética (CARVALHO, 2001).

Nesse sentido, um dos objetivos específicos propostos pelas coordenadoras do projeto consiste em conhecer práticas, representações e apropriações de leitura dos gradua(n)dos em Letras e em Pedagogia e, a partir dos resultados encontrados, produzir respostas às seguintes questões:

O que os alunos das pós-graduações e das licenciaturas das instituições pesquisadas
leem? Com qual frequência? Em que lugares e contextos? Em que formas materiais?
Com quais objetivos? De que estratégias lançam mão? Esses alunos realizam outras
leituras além das pedidas pelos programas de pós e de licenciatura? Quais as
concepções que têm de leitura, de ensino de leitura e de práticas de leitura no espaço
escolar? Que experiências acionam para realizar suas leituras? (PROJETO, 2013,
p. 17).

Tendo em vista o caráter exploratório-descritivo do referido projeto, o principal instrumento de coleta de dados foi um questionário composto por 85 questões abertas e fechadas, divididas em sete eixos, produzido pelo coletivo dos grupos de pesquisa, sob orientação e revisão dos coordenadores (DALVI; BATISTA; PLASTER, 2017). Finalizada fase de elaboração, o questionário foi aplicado a 455 alunos matriculados no primeiro semestre dos cursos de Letras e Pedagogia das instituições parceiras.

Neste artigo, analisaremos o conjunto de dados produzidos com base no quinto eixo, "Dimensões valorizadas na leitura e Preferências de leitura", composto pelas questões abertas, 
a saber: 58 - Indique um livro (título e autor) que o tenha interessado/sensibilizado em particular; e 59 - Justifique sua indicação.

Para isso, dialogaremos com o texto "Leitura, estudantes de licenciatura e indicadores sócio-econômico-culturais: dados preliminares de uma pesquisa”, produzido em 2017, por Maria Amélia Dalvi, Ana Karen Costa Batista e Tallita Braga Plaster, que apresenta o perfil dos estudantes que responderam ao questionário. Além disso, recorreremos a estudos recentes desenvolvidos pelo Grupo de Pesquisa Literatura e Educação/Ufes, a saber: Rosana Carvalho Valtão (2016), Rossana dos Santos Santana Rubim (2016) e Ronis Faria de Souza (2016), que, de algum modo, dialogam com a temática da leitura e com as questões de análise já mencionadas.

O referencial teórico que embasará esse estudo assenta-se no pensamento de Roger Chartier, a partir das noções conceituais de práticas, representações e apropriações. Filiado à História Cultural, esse autor entende que a realidade é produzida a partir de representações, ou seja, de classificações, divisões e delimitações que organizam a apreensão do mundo social (CHARTIER, 1990). As práticas são modos, usos e costumes construídos a partir das representações, dando significado à realidade. $\mathrm{O}$ modo como os sujeitos se apropriam das práticas sociais revelam preferências distintivas, marcando seus traços de similitude com determinadas comunidades interpretativas com as quais se relacionam.

Para discutir questões relacionadas à Literatura e seu ensino, lançaremos mão dos estudos de Rouxel (2014) e Dalvi (2013), além de outros trabalhos que dialoguem com o objeto de análise.

\section{Descrição e análise dos dados}

Do total de 455 alunos investigados, setenta e quatro (74) não responderam às questões 58 e 59. Dos trezentos e oitenta e um (381) respondentes, observou-se que os livros indicados, ou seja, aqueles que, de alguma forma, despertaram-lhes o interesse, figuram em diferentes categorias literárias ${ }^{2}$, tais como: Literatura Estrangeira (ficção norte-americana, inglesa, literatura canônica etc.), Literatura Brasileira (canônica e não-canônica), Literatura InfantoJuvenil, Literatura Religiosa, Literatura de Autoajuda, formação acadêmico-profissional e obras não identificadas, sem título e de outros gêneros literários.

\footnotetext{
${ }^{2}$ Tendo em vista que este estudo apoiou-se nos procedimentos metodológicos da pesquisa documental, elegemos as referidas categorias, a fim de facilitar a classificação e sistematização dos dados. (BRAVO, 1991, p. 290).
} 
Um primeiro ponto a se destacar, a partir dos livros indicados é que eles leem. São leituras bastante variadas que vão desde a Literatura canônica a livros técnicos, que apontam para diferentes perfis de leitores, ligados a diferentes comunidades interpretativas. Esses dados reforçam o que foi evidenciado nas pesquisas de Valtão (2016) e Rubim (2016) quanto às preferências de leitura dos alunos do Ifes campus-Alegre e Ifes campus-São Mateus, respectivamente. As pesquisadoras constataram que os estudantes apresentaram uma inclinação explícita por títulos de literatura estrangeira, sobretudo os chamados best-sellers. Livros das categorias religiosas, autoajuda e técnica também foram citados pelos alunos, embora não figurem entre os preferidos (VALTÃO, 2016; RUBIM, 2016), em contraposição ao que relataram os graduandos de Letras e Pedagogia.

Nesse contexto, as pesquisas de Valtão (2016) e Rubim (2016), somadas a esta, revelam que tanto os alunos do Ensino Médio quanto os estudantes das universidades investigadas possuem, em sua maioria, práticas de leitura literária. No entanto, boa parte dessas leituras diverge das obras recomendadas pelos professores de literatura. Frente a esse impasse, Ane Rouxel (2014) defende que o ensino de literatura precisa instituir alunos como sujeitos leitores, acolhendo suas reações subjetivas com o texto literário (seja ele canônico ou não). É preciso, portanto, renunciar à atividade de leitura concebida como lugar de aquisição programada de saberes para "engajar os alunos na aventura interpretativa, com seus riscos, suas instabilidades, suas contradições, suas surpresas, suas descobertas, mas também seus sucessos" (ROUXEL, 2014, p. 21).

Voltando às obras indicadas, os dados demonstraram, ainda, que as práticas de leitura literária dos respondentes foram construídas em contextos escolares e não-escolares. A despeito disso, independente de ser uma obra canônica, um best-seller ou um livro religioso, a experiência estética, as metamorfoses que o leitor imprimiu ao texto, tornando-o seu (ROUXEL, 2014), foram ressaltadas inúmeras vezes pelos estudantes, mostrando que esse encontro íntimo, sensível com a obra, foi fundamental para sua formação como leitor.

Não estamos, aqui, defendendo a aclamação das leituras particulares, da liberdade de interpretação dos alunos em detrimento da análise dos textos com clareza e com rigor, a partir de terminologias e conceitos que, com o tempo, se transformarão em ferramentas de leitura. No entanto, rejeitar as preferências literárias dos alunos não contribui para que eles tenham o "encontro com textos mais densos e mais capazes de transformar a visão de mundo, as maneiras de sentir e pensar" (CHARTIER, 1999, p. 104). 
Tendo em vista a grande quantidade de dados a serem sistematizados por tratarem-se de duas questões abertas, foram estabelecidas sete categorias de análise, agrupando as obras a partir das classes literárias às quais pertencem. Na sequência, foram feitas as descrições das obras postas em diálogo com o perfil sócio-econômico-cultural dos estudantes.

\title{
Nota sobre os "não-respondentes"
}

Conforme já mencionamos, setenta e quatro (74) alunos não responderam às questões 58 e 59. Poderíamos apresentar uma série de suposições para essa não-resposta. No entanto, um ponto preocupante em relação a esses dados reside no fato de que, talvez, esses estudantes podem não ter vivenciado a prática da leitura literária ao longo de sua formação na Educação Básica. Dizemos isso, pois acreditamos que o sujeito que já vivenciou a experiência estética guarda em sua memória as percepções, os valores, suas impressões sobre aquela leitura. Ainda que tenha sido uma única leitura.

A nosso ver, colabora para esse quadro o fato de o texto literário não ser tomado como centro, mas como objeto figurativo no ensino de Literatura, em que se valoriza a leitura de resumos, de textos fragmentados inseridos nos livros didáticos, o estudo historiográfico das escolas literárias, os aspectos estilísticos da linguagem, em detrimento da leitura do texto e das percepções do aluno sobre a obra.

Tendo em vista a problemática que envolve o ensino de Literatura e formação do leitor, são caras as palavras de Dalvi, ao afirmar que na escola

\begin{abstract}
Os textos literários são apresentados em desarticulação com o mundo da vida, com a história e o contexto social-econômico-cultural. Principalmente para alunos economicamente desfavorecidos o acesso ao circuito literário é, às vezes, tão impensável quanto um cruzeiro para as ilhas gregas. No entanto, a escola se esquece de que talvez fosse o caso de apurar o olhar para a análise de formas literárias populares, como a música que toca nas rádios, a novela, o filme de Hollywood, o grafite como poesia visual etc., buscando nessas manifestações seus pontos de contato com a dita alta literatura, a fim de mais construir pontes que erguer muros - e com isso estamos no oposto de defender um "barateamento" estético ou político do literário. Sugerimos um ponto de partida que permita, ao fim e ao cabo, a retomada dessa produção da indústria cultural sob um viés muito mais crítico. (DALVI, 2013, p.74-75).
\end{abstract}

Diante do não posicionamento desses respondentes, ou da possibilidade de nos depararmos com graduandos que ainda não vivenciaram a experiência literária, acreditamos que esta pesquisa possa contribuir para que a Universidade em seu compromisso social com as demandas da população, sobretudo com a formação de professores da Educação Básica, possa propor ações voltadas aos estudantes, a fim de que, antes de tudo, eles se tornem sujeitos leitores, pois são nas experiências de leituras particulares que o texto ganha vida e produz 
sentidos (ROUXEL, 2014) e, por consequência, possam produzir mudanças significativas na formação dos futuros professores.

\section{Literatura Estrangeira}

Identificamos Cento e oitenta e quatro (184) indicações de literatura estrangeira. Dessas, aproximadamente $90 \%$ são livros de ficção, chamados literatura de massa e que apareceram repetidas vezes. Os $10 \%$ restantes são livros consagrados pela crítica literária, considerados literatura canônica. Seguem algumas obras e comentários dos estudantes:

Quadro 1 - Literatura Estrangeira - Best-seller

\begin{tabular}{ll}
\hline \multicolumn{1}{c}{ Título } & \multicolumn{1}{c}{ Comentários dos participantes } \\
\hline A Cabana & "Além de ter me emocionado, me fez refletir". \\
A Culpa é das Estrelas & $\begin{array}{l}\text { "Envolve o leitor, linguagem fácil"; "Me emocionei muito com a } \\
\text { história dos personagens"; }\end{array}$ \\
$\begin{array}{l}\text { A Menina que Roubava } \\
\text { Livros }\end{array}$ & $\begin{array}{l}\text { "Fala sobre a segunda guerra mundial e como ela era vista pelo povo } \\
\text { que sofria: o judeu”. }\end{array}$ \\
$\begin{array}{l}\text { Harry Potter } \\
\text { O Caçador de Pipas }\end{array}$ & $\begin{array}{l}\text { "É uma história que mexe com o psicológico e faz com que mude o jeito } \\
\text { de pensar". }\end{array}$ \\
$\begin{array}{l}\text { O Menino do Pijama } \\
\text { Listrado } \\
\text { Querido John }\end{array}$ & "Trata-se de uma história vivida na Segunda Guerra Mundial". \\
\hline
\end{tabular}

Fonte: Elaboração própria.

Quadro 2 - Literatura Estrangeira - Canônica

\begin{tabular}{|c|c|}
\hline Título & Comentários dos participantes \\
\hline A Odisseia & $\begin{array}{l}\text { "Um livro que nos mostra a coragem de persistir mesmo quando } \\
\text { pensamos que tudo está acabado". }\end{array}$ \\
\hline Cem Anos de Solidão & "Ensina que para o amor verdadeiro o tempo não é inimigo". \\
\hline Ensaio sobre a Cegueira & Sem justificativa. \\
\hline $\begin{array}{l}\text { O Conde de Monte } \\
\text { Cristo }\end{array}$ & $\begin{array}{l}\text { "Com } 12 \text { anos, foi o primeiro livro, com uma história complexa, que } \\
\text { me chamou a atenção". }\end{array}$ \\
\hline O Pequeno Príncipe & "Um livro incrivel”, "É um clássico". \\
\hline Romeu e Julieta & "Histórias de romance me fascinam". \\
\hline Terra Sonâmbula & $\begin{array}{l}\text { "Foi o melhor livro que já li em toda minha vida. Trata-se de um } \\
\text { homem que acredita na política e nos governantes e, devido a uma } \\
\text { idealização, morre fuzilado". }\end{array}$ \\
\hline Tristão e Isolda & "Motiva a ler mais livros". \\
\hline
\end{tabular}

Fonte: Elaboração própria.

As indicações dos respondentes revelam que, embora haja, por parte da crítica, uma rejeição a essas obras, por considerá-las sem valor estético, criadas para atender aos interesses do mercado, a literatura estrangeira, sobretudo os best-sellers, tem figurado como um dos gêneros mais lidos na contemporaneidade. Esses dados corroboram os resultados das pesquisas 
realizadas pelo grupo Literatura e Educação/Ufes (SOUZA, 2016; VALTÃO, 2016; RUBIM 2016), que constataram a preferência tanto de alunos quanto de professores do Ensino Médio pela literatura de massa na atualidade.

Uma das razões para essa preferência reside no fato de que, de algum modo, essas obras exprimem os anseios dos leitores. Seja pela linguagem fácil, pela narrativa envolvente ou pela identificação com os personagens, essas obras, de algum modo, retratam o leitor, seus valores, sua visão de mundo, suas questões existenciais.

Além disso, os comentários dos sujeitos pesquisados evidenciam que tanto os best-sellers quanto os clássicos promoveram uma leitura impactante, desestabilizadora, na medida em que possibilitaram uma reflexão sobre questões existenciais do mundo hodierno e, ao mesmo tempo, provocaram um conjunto de sensações emotivas concretizadas por meio da experiência estética.

Com base nessas considerações, parece-nos que os graduandos concebem a literatura ficcional estrangeira como uma arte tanto de fruição quanto de reflexão sobre a vida e sobre a sociedade atual. São leitores que, enquanto leem, buscam entretenimento e compreensão acerca da realidade em que vivem.

Refletindo sobre essas indicações, aliadas à faixa etária dos respondentes - 78\% possuem entre 18 e 23 anos - (DALVI; BATISTA; PLASTER, 2017), não podemos ignorar o fato de que a indústria cultural, articulada aos sistemas de comunicação, tem exercido forte influência sobre as preferências de leitura desse público na sociedade atual.

Um dos fatores que contribuem para esse fenômeno reside no fato de que a arte, assim como outros setores da sociedade, está articulada ao mercado econômico. Este, aliado aos meios de comunicação de massa, estimula o consumo de bens culturais em escala global, contribuindo para que a identidade dos sujeitos se torne desvinculada de tempos, lugares e tradições determinadas. Desse modo, as identidades vão se tornando múltiplas, instáveis, orientadas pelas necessidades e interesses do sujeito na sociedade (BAUMAN, 2005).

Cumpre destacar, ainda, que os sujeitos da pesquisa fazem parte, assim como nós, de uma sociedade guiada pela "onda" do momento, que seduz para o consumo desenfreado, para o frenesim por novidades e diversão. Uma época de valorização do presente contínuo, do prazer hedonístico e da hiperindividualidade. Desse modo, "os indivíduos adotam os objetos, as modas, as fórmulas de lazer elaboradas por organizações especializadas, porém de acordo com suas conveniências, aceitando isto e não aquilo, combinando livremente os elementos programados" (LIPOVETSKY, 2005, p. 85). 
Com base nessas informações, é possível perceber que as obras literárias indicadas pelos estudantes podem ser vista como bens de consumo que visam à satisfação de seus desejos emocionais, suas motivações privadas, na tentativa de "dar uma resposta tangível, ainda que superficial, à eterna pergunta: quem sou eu?” (LIPOVETSKY, 2010, p.45).

Nesse cenário, é possível dizer que a literatura de massa está preparada para atender aos interesses de consumo desse público. Segundo Sodré (1988, p.16), essas obras são construídas a partir de "conteúdos fabulativos (e, portanto, a intriga com sua estrutura clássica de princípiotensão, clímax, desfecho e catarse), destinados a mobilizar a consciência do leitor, exasperando a sua sensibilidade". Os personagens são fortemente caracterizados, de modo a estabelecer uma conexão com o perfil do leitor, a linguagem é coloquial, bem próxima da oralidade, marcada por uma abundância de diálogos, permitindo uma "adesão mais intensa do leitor à trama e de uma exploração sistemática da curiosidade do público" (SODRÉ, 1988, p.17).

Apesar de serem rechaçados pela crítica e pela academia como livros sem qualquer reconhecimento artístico, aliados aos interesses do mercado, somos levados a crer, com base nos comentários dos respondentes, que a literatura de massa proporciona o hábito de leitura por prazer, como forma de entretenimento. Nesse sentido, concordamos com Paes (1990, p. 28) ao defender que essa literatura "adquire o sentido de degrau de acesso a um patamar mais alto onde o entretenimento não se esgota em si, mas traz consigo um alargamento da percepção e um aprofundamento da compreensão das coisas do mundo".

\section{Literatura Brasileira}

Nesta categoria, apareceram setenta e nove (79) indicações de obras, subdivididas em dois grupos: literatura canônica e não-canônica. Em literatura canônica (mais de 88\%), os livros listados no Quadro 3 foram citados repetidas vezes. Doze por cento (12\%) dos títulos foram categorizados na pesquisa como best-sellers brasileiros ou literatura não-canônica (Quadro 04).

Quadro 3 - Literatura Brasileira - Canônica

\begin{tabular}{ll}
\hline \multicolumn{1}{c}{ Título } & \multicolumn{1}{c}{ Comentários dos participantes } \\
\hline Capitães da Areia & "Foi uma recomendação do professor, mas, quando comecei a ler, \\
& fiquei impressionada com a história de cada personagem", "fácil \\
O Cortiço & leitura, interessante, retratando, infelizmente, uma realidade". \\
& "Li esse livro no Ensino Médio, achei superinteressante, pois retratava \\
Vidas Secas & ocotidiano de uma sociedade de um modo bem realista". \\
Senhora & "Todo ser humano precisa fazer a leitura deste livro para crescimento \\
& "Émano".
\end{tabular}




\begin{tabular}{|c|c|}
\hline Dom Casmurro & $\begin{array}{l}\text { "Sempre ouvi falar do livro e personagens, até que ganhei o livro de } \\
\text { presente". }\end{array}$ \\
\hline Menino de Engenho & $\begin{array}{l}\text { "Um livro que traz ação e ficção, uma história parece real incidentes do } \\
\text { dia a dia[sic], uma infância sofrida e confusa, mas com um resultado } \\
\text { no final, uma realidade do que cada criança passa". }\end{array}$ \\
\hline $\begin{array}{l}\text { Uma Aprendizagem ou } \\
\text { O Livro dos Prazeres }\end{array}$ & "Nos ajuda a refletir sobre nós mesmos". \\
\hline Grande Sertão Veredas & $\begin{array}{l}\text { "Palavreado criativo, amor pelo trabalho/características do autor: } \\
\text { proporcionamento de inúmeros conhecimentos". }\end{array}$ \\
\hline $\begin{array}{l}\text { Carlos Drummond de } \\
\text { Andrade }\end{array}$ & "Muito sentimental". \\
\hline Feliz Ano Velho & "Linda história". \\
\hline
\end{tabular}

Fonte: Elaboração própria.

Quadro 4 - Literatura Brasileira - Não-canônica

\begin{tabular}{|c|c|}
\hline Título & Comentários dos participantes \\
\hline Fim & $\begin{array}{l}\text { "O tratamento da morte por uma inusitada perspectiva e a reflexão que } \\
\text { permite gerar". }\end{array}$ \\
\hline O Cheiro do Ralo & "Porque é bom". \\
\hline Felicidade & "Gostei muito da leveza que trata a cada crônica/palavra". \\
\hline Olga & $\begin{array}{l}\text { "É um livro que conta a história de Olga Benário Prestes, judia e } \\
\text { comunista, que foi companheira de Luís Carlos Prestes [...]". }\end{array}$ \\
\hline O Alquimista & $\begin{array}{l}\text { "Gostei muito desse livro, pois mostra que, às vezes, estamos tão perto } \\
\text { do que queremos, mas não percebemos [...]". }\end{array}$ \\
\hline Verônica Decide Morrer & $\begin{array}{l}\text { "Nessa história, Verônica tenta cometer o suicídio, e, depois disso, o } \\
\text { médico diz que ela tem pouco tempo de vida. Com isso, ela aprende a } \\
\text { lutar e querer viver". }\end{array}$ \\
\hline Diário de um Mago & $\begin{array}{l}\text { "É o relato da história dele em um rito de passagem da religião contado } \\
\text { em primeira pessoa, esse foi o toque especial que ele deu no livro, e eu } \\
\text { indico muito!!" }\end{array}$ \\
\hline Brida & $\begin{array}{l}\text { "Este livro abre nossa mente, faz com que paremos de ser um tanto } \\
\text { preconceituosos". }\end{array}$ \\
\hline
\end{tabular}

Fonte: Elaboração própria.

Em relação à literatura canônica, os comentários dão a ver a importância da escola na formação do gosto do leitor por essas obras. De acordo com Bourdieu (2011), o sistema de ensino atua na conservação e consagração do campo erudito. É ele o responsável por “assegurar a reprodução do sistema dos esquemas de ação, de expressão, de concepção, de imaginação, de percepção e de apreciação social" (BOURDIEU, 2011, p. 117), de modo a formar sujeitos aptos a consumir e reproduzir a cultura dita legítima. Nesses moldes, alguns autores acabam tendo seus nomes transformados em uma "marca", ou seja, em uma referência a uma literatura elevada que deve ser lida, admirada e copiada. Por outro lado, os graduandos também revelam que a leitura dos cânones, embora seja vista por alguns alunos como obras de linguagem arcaica e/ou rebuscada, com uma temática distante do cotidiano, pode promover tanto o prazer estético quanto o debate sobre a forma como a sociedade e os sujeitos são retratados na literatura de seu 
próprio país. E que, muitas vezes, não estão distantes das problemáticas individuais e sociais da atualidade.

Em relação às obras de literatura brasileiras de ordem não canônicas, os comentários indiciam práticas de leitura não atreladas ao compromisso avaliativo, ao dever, mas ligadas ao entretenimento, ao prazer, e aos sentidos construídos pelo leitor no ato de leitura a partir de suas experiências pessoais. Nesse contexto, entendemos, com Tzvetan Todorov, que os respondentes, enquanto leitores não profissionais, leem obras literárias

não para dominar um método de ensino, tampouco para retirar informações sobre as sociedades a partir das quais foram criadas, mas para nelas encontrar um sentido que lhe permita compreender melhor o homem e o mundo, para nelas descobrir uma beleza que enriqueça sua existência; ao fazê-lo, ele compreende melhor a si mesmo. $\mathrm{O}$ conhecimento da literatura não é um fim em si, mas uma das vias régias que conduzem à realização pessoal de cada um. (TODOROV, 2009, p. 32-33).

\section{Literatura Religiosa}

Houve trinta e nove (39) indicações de obras religiosas. Destas, oito (8) estudantes indicaram a Bíblia. Trinta e um (31) graduandos indicaram livros com temática religiosa.

Quadro 5 - Literatura Religiosa

\begin{tabular}{|c|c|}
\hline Título & Comentários dos participantes \\
\hline Bíblia & $\begin{array}{l}\text { "Nos concede muita aprendizagem, nos ensina a sermos seres humanos } \\
\text { melhores"; "Não existe livro que mais possa sensibilizar o ser humano } \\
\text { do que o que Nela contém, utilizando Jesus como chave"; "Porque } \\
\text { aprendo muito sobre a palavra de Deus". }\end{array}$ \\
\hline Retalhos de I & "Literatura religiosa, agradável e gostosa". \\
\hline Fé e Paixão & $\begin{array}{l}\text { "É um livro onde me identifiquei bastante, traz consolo, palavras de } \\
\text { motivação e ótimos exemplos a ser seguido". }\end{array}$ \\
\hline $\begin{array}{l}\text { O Preço } \\
\text { Escolha }\end{array}$ & $\begin{array}{l}\text { "Ainda estou lendo, se trata de um livro espírita e parece ser muito } \\
\text { bom". }\end{array}$ \\
\hline Vivendo com a Morte & $\begin{array}{l}\text { "Ensina o processo da morte, suas etapas e como enfrentar esse } \\
\text { processo da dor e perda". }\end{array}$ \\
\hline Laços Abertos & $\begin{array}{l}\text { "É espirita"; Kairós [sic]: "Gosto muito de livros religiosos e que me } \\
\text { fazem sentir bem. Me faz sentir melhor depois da leitura". }\end{array}$ \\
\hline $\begin{array}{l}\text { Tempo de Saudades e } \\
\text { Esquecimentos }\end{array}$ & $\begin{array}{l}\text { "Já tem um tempo que leio somente para me distrair, e a leitura religiosa } \\
\text { é a que mais me atrai". }\end{array}$ \\
\hline
\end{tabular}

Fonte: Elaboração própria.

Essas indicações, a nosso ver, refletem traços do perfil cultural dos respondentes, pois mais da metade deles $(77,6 \%)$ são adeptos a alguma religião (DALVI; BATISTA; PLASTER, 2017). De acordo com Bernardo Lewgoy (2004), a leitura de livros religiosos pode ser compreendida a partir das mudanças no campo religioso, da escolarização dos membros dessas instituições e do interesse do mercado editorial nesse público. Segundo o autor, os 
neopentecostais, que alcançaram um crescimento vertiginoso nos últimos 20 anos, são os responsáveis pela maior parte da circulação e aquisição de novas Bíblias. Contudo,

[o]s dados disponíveis indicam um crescimento simultâneo de tendências denominacionais e interdenominacionais, em ritmos e proporções ainda não suficientemente estimadas, mas que indicam que emergem neoleitores entre os convertidos ao lado de leitores com um interesse literário renovado em todas as denominações, novas e antigas, históricas e pentecostais, todos com variados interesses, que incluem curiosidades sobre títulos e autores de outras Igrejas, de modo que a geometria das diferenças internas só parcialmente é válida para entender as atuais leituras nesse universo. Para ainda seguir as sugestões de Roger Chartier, apostamos na hipótese de que a cartografia do leitorado evangélico é simultaneamente formada das fronteiras e passagens, promovendo um intenso trânsito literárioreligioso no interior desse universo. (LEWGOY, 2004, p. 19).

À luz das considerações de Lewgoy (2004), entendemos que os leitores dessas obras não são mais aqueles que acreditam tão somente na fala de um líder religioso, mas investem em sua formação espiritual, tendo a leitura como um meio para alcançar esse conhecimento. Em diálogo com os comentários dos respondentes, percebemos que eles compreendem a leitura dessas obras como forma de aquisição de conhecimentos, por meio de aconselhamentos de cunho espiritual, que visam a instrui-los sobre as condutas humanas mais adequadas para alcançarem o equilíbrio emocional e a felicidade. É, ainda, uma leitura que dá prazer, pois provoca um efeito anestésico às angústias da sociedade contemporânea. O leitor procura nessas obras, além de entretenimento, consolo, um tipo de escape psicológico frente às agruras da vida cotidiana, na busca pelo gerenciamento de si.

\section{Literatura de Autoajuda}

Na pesquisa, vinte e cinco (25) alunos indicaram livros que podem ser considerados como Literatura de autoajuda. Destes, catorze (14) sugeriram títulos variados, enquanto onze (11) estudantes indicaram várias obras do autor Augusto Cury, como se pode observar no Quadro 6.

Quadro 6 - Literatura de Autoajuda

\begin{tabular}{|c|c|}
\hline Título & Comentários dos participantes \\
\hline $\begin{array}{l}\text { Como se dar bem com } \\
\text { quem você quer bem }\end{array}$ & $\begin{array}{l}\text { "Trata das relações humanas, o que queremos que o outro 'faça' deve } \\
\text { ser feito primeiro por mim [...]". }\end{array}$ \\
\hline Por que estou aqui? & $\begin{array}{l}\text { "O livro mostra alguns detalhes do cotidiano que não nos damos conta, } \\
\text { até que alguém o diga". }\end{array}$ \\
\hline $\begin{array}{l}\text { Você pode curar sua } \\
\text { vida }\end{array}$ & $\begin{array}{l}\text { "É um livro único, de aprendizagem, conselhos, faz o leitor pensar, } \\
\text { perceber a si mesmo. Acho que foi o livro que mais me ajudou. Li a } \\
\text { primeira vez há uns vinte anos. Recomendo. }\end{array}$ \\
\hline Feliz por nada & "Mudou meu olhar sobre a vida, sobre os valores das coisas". \\
\hline Futuro da Humanidade & $\begin{array}{l}\text { "É um autor interessante, seus livros são motivadores e nos tornam mais } \\
\text { críticos em relação a algumas coisas na sociedade moderna". }\end{array}$ \\
\hline
\end{tabular}




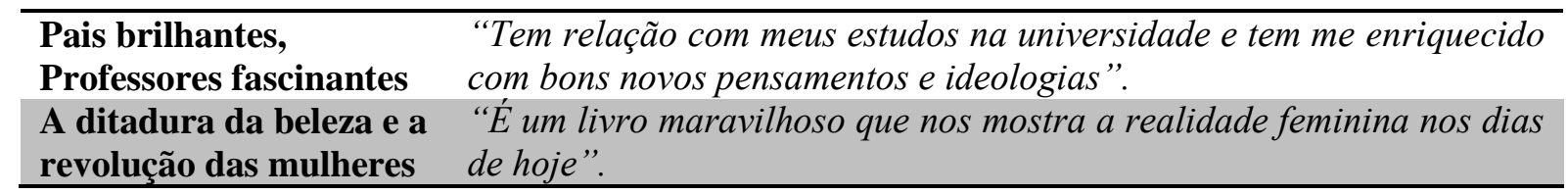
Fonte: Elaboração própria.

Essas indicações apontam para um interesse dos graduandos por leituras que retratem seus dilemas individuais no contemporâneo, apresentando respostas sobre como enfrentá-los e vencê-los. Desse modo, os respondentes dão a ver que a leitura literária que os marcou tem um caráter formativo e informativo. A leitura prazerosa é aquela que traz satisfação às suas necessidades psicológicas, que busca resolver conflitos humanos (fraqueza, vulnerabilidade) que causam desequilíbrio cognitivo e espiritual.

Embora haja nas obras de autoajuda uma tendência a provocar nos leitores a excitação por meio de um discurso de empoderamento, incentivando-os a lançarem-se em busca de seus sonhos e da felicidade, por meio de metas e objetivos pré-definidos (CHAGAS, 2001), um olhar mais detido sobre os comentários revela que os graduandos, enquanto sujeitos pós-modernos, descentrados, buscam encontrar nesses textos estratégias para construir seu eu de maneira reflexiva, isto é, um recurso para a construção da identidade e do disciplinamento interior. Desse modo, podem ser considerados sujeitos cujas identidades se tornam cada vez mais fragmentadas, algumas vezes contraditórias e não resolvidas, permeadas por processos de identificação provisórios, variáveis e problemáticos (HALL, 2005).

\section{Literatura Infantil e Infanto-juvenil}

Nesta categoria, houve apenas um (1) livro que definimos como literatura infantil: Chapeuzinho Amarelo. Os outros vinte (20) títulos indicados foram classificados como literatura infanto-juvenil (Quadro 7).

Quadro 7 - Literatura Infantil e Infanto-juvenil

\begin{tabular}{|c|c|}
\hline Título & Comentários dos participantes \\
\hline Chapeuzinho Amarelo & "Ajuda a quebrar paradigmas". \\
\hline $\begin{array}{l}\text { Depois daquela } \\
\text { viagem }\end{array}$ & "Por ser uma história real e do cotidiano". \\
\hline A bailarina fantasma & "Foi um livro que cativou o hábito de leitura". \\
\hline $\begin{array}{l}\text { Tudo o que é sólido } \\
\text { pode derreter }\end{array}$ & "Proporciona outro modo de ver as escolhas literárias". \\
\hline $\begin{array}{l}\text { Alice no país das } \\
\text { maravilhas }\end{array}$ & $\begin{array}{l}\text { "É um livro extremamente complexo pela sua simplicidade. As coisas } \\
\text { vividas por Alice e seus questionamentos pegam o leitor despreparado } \\
\text { para tamanha viagem". }\end{array}$ \\
\hline Tchau & "Um livro com histórias comoventes. Li na infância". \\
\hline
\end{tabular}




\begin{tabular}{ll}
\hline $\begin{array}{l}\text { A marca de uma } \\
\text { lágrima }\end{array}$ & $\begin{array}{l}\text { "Identificação com a personagem principal e a fase que a mesma } \\
\text { Isso ninguém me tira }\end{array}$ \\
& $\begin{array}{l}\text { "O livro é indicado para jovens e fala de assuntos bobos, mas que todas } \\
\text { as pessoas já vivenciaram e nos leva a pensar o que realmente queremos } \\
\text { para nossa e futuro". }\end{array}$ \\
\hline
\end{tabular}

Fonte: Elaboração própria.

As indicações acima lançam luzes sobre obras destinadas a adolescentes e nos levam a refletir sobre a importância que elas têm na iniciação à leitura literária. Por meio das indicações e comentários, não foi possível identificar se essas leituras foram feitas por orientação do professor, mas os relatos dão a ver que a identificação com as obras está relacionada à satisfação das necessidades e expectativas pessoais dos leitores.

Nesse sentido, parece-nos que a escola e os adolescentes caminham em sentidos opostos. Enquanto a escola prioriza o ensino dos gêneros literários, das fichas de leitura, da periodização e de análise dos elementos estéticos da linguagem, os adolescentes são motivados a ler por sua identificação com o personagem, por uma sensibilização em relação às problemáticas tratadas na obra. A partir dos comentários dos estudantes, somos levados a crer que o interesse por tais obras não foi motivado pelo reconhecimento da importância da leitura para a construção de um leitor crítico, agente construtor de significados - embora pactuemos desses princípios -, e sim por interesses condizentes à sua personalidade e ao seu desenvolvimento intelectual.

Convém destacar que a identificação com obras infanto-juvenis pode estar, mais uma vez, relacionada ao fato de que $78 \%$ dos respondentes são jovens entre 18 e 23 anos (DALVI; BATISTA; PLASTER, 2017, p. 10). Caso tal reflexão seja válida, ela traz consigo uma preocupante constatação: as obras literárias (cânones nacionais ou não) com as quais esses sujeitos tiveram contato no Ensino Médio não trouxeram uma contribuição significativa em sua formação como leitor. Desse modo, esta pesquisa colabora para o campo de formação de professores de Letras e Pedagogia, ao evidenciar que o leitor idealizado pela crítica e pelos professores universitários - que, supostamente, deveria deixar o Ensino Médio com um vasto repertório de leituras literárias canônicas, com habilidades de análise e interpretação de textos literários, com conhecimento de recursos estilísticos de linguagem própria da obra e do autornão condiz com o leitor real está chegando às universidades. 


\section{Livros de formação acadêmico-profissional}

Foram identificados vinte e seis (26) títulos que figuram como não-literários. Tratam-se de livros técnicos voltados para as áreas de Filosofia, Pedagogia, Política, Direito, História, Empreendedorismo e Letras.

Quadro 8 - Livros de formação acadêmico-profissional

\begin{tabular}{|c|c|}
\hline Título & Comentários dos participantes \\
\hline Os pingos nos is & "Compreender os caminhos dos educadores". \\
\hline O Príncipe & $\begin{array}{l}\text { "É um livro que nos desperta a entender a ética e o comportamento da } \\
\text { política". }\end{array}$ \\
\hline Pedagogia do Oprimido & $\begin{array}{l}\text { "Ele diz que o oprimido só se liberta em comunhão e ele também liberta } \\
\text { seu opressor". }\end{array}$ \\
\hline Convite à Filosofia & "Autoconhecimento". \\
\hline Geração de Valor & "O livro fala sobre empreendorismo [...]". \\
\hline
\end{tabular}
Fonte: Elaboração própria.

Esta categoria, a nosso ver, está relacionada com uma concepção de leitura próxima daquela descrita sobre os livros de autoajuda, na medida em que trazem um saber útil que lhes ajudará a lidar com as necessidades reais do cotidiano, seja em sua formação profissional ou pessoal. Tanto as obras indicadas quanto os comentários levam-nos a inferir que as leituras que impactaram os graduandos dessa categoria podem ter sido, em alguma medida, influenciadas por formações acadêmicas em outras áreas, já que, segundo Dalvi, Batista e Plaster (2017), $5,3 \%$ dos respondentes já tinham curso superior completo em outras áreas, como: Administração, Agronegócio, Análise de Sistemas, Ciências Biológicas, Educação Artística, Educação Física, Estética e Cosmética, Filosofia, Jornalismo, Letras, Licenciatura em Educação Física, Licenciatura em Música, Magistério, Pedagogia, Psicologia, Publicidade e Propaganda e Tecnologia em Alimentos.

Com base nos comentários, é possível perceber que a experiência de leitura se constituiu especialmente pelas temáticas formativas abordadas em tais obras, pelas discussões que promovem em campos específicos do conhecimento. Contudo, denunciam uma concepção de leitura como meio para aquisição de conhecimentos, sem uma participação ativa do leitor, que se identifica com o texto, pois encontra nele um saber pronto e acabado. Um saber útil que agrega à sua formação.

\section{Obras não identificadas, sem título e de outros gêneros literários}

Esta categoria foi criada para situações inusitadas, nas quais não foi possível: a) a identificação em sites de busca de alguns títulos indicados (Os monarcas, Dosder, Um canto 
para Leibsteir); b) não houve indicação do título da obra, apenas o comentário ("Livro com conteúdo muito bom e que nos leva a querer ler"; "Esse livro fez com que eu olhasse de uma forma diferente para as pessoas"). Houve, ainda, duas indicações do Mangá Once Piece: “Tratase de um mangá feito com bastante maestria quanto à ação, sentimentos e nomeações pessoais”.

Nesta categoria, chamou-nos a atenção duas indicações de Mangás. Bisconcim (2012) revela que, no Brasil, tem crescido o número de leitores brasileiros que se interessam por Mangás, revistas em quadrinhos em estilo japonês. Segundo a autora, embora não seja considerado por críticos e teóricos como literatura, o mangá preenche os mesmos requisitos dos textos literários, ao oferecer "entretenimento, fantasia e, porque não dizer, o valor estético" (BISCONCIM 2012, p. 166), ou seja, essas obras também têm colaborado para despertar o gosto pela leitura literária.

\section{Considerações Finais}

O objetivo deste estudo foi descrever e analisar o conjunto de dados produzidos pelo quinto eixo, "Dimensões valorizadas na leitura e Preferências de leitura", do questionário produzido pelo Projeto PROCAD. Foram analisadas as seguintes questões abertas: 58 - Indique um livro (título e autor) que o tenha interessado/sensibilizado em particular; e 59 - Justifique sua indicação.

Para fins de organização e sistematização da análise, os dados foram organizados em sete (07) categorias: 01) Literatura estrangeira; 02) Literatura Brasileira; 03) Literatura religiosa; 04) Literatura de autoajuda; 05) Literatura infanto-juvenil; 06) Livros não-literários e 07) outros. A análise empreendida procurou considerar o contexto social e cultural que envolve o autor, o leitor e a obra, pois acreditamos que esses aspectos exercem papel fundamental sobre as preferências de leituras dos respondentes.

De modo geral, foi possível perceber que a literatura marginal (best-sellers, religiosa e autoajuda) desperta maior interesse dos graduandos em detrimento da literatura erudita. Isso se deve ao fato de que tanto o público jovem quanto os adultos se identificam com obras que fazem parte do seu tempo e espaço: seja pela temática, pelo perfil dos personagens, pela linguagem, pela discussão dos desafios da vida diária, os leitores preferem textos que representem sua singularidade subjetiva, que expressem sua liberdade para viver e poderem escolher seu modo de existência sem a ilusão no futuro nem as opressões do passado.

Nesse contexto, a indústria cultural, por meio da literatura de massa, está preparada para atender às demandas desse público, oferecendo-lhes obras que vão ao encontro dos seus 
interesses particulares. A despeito der ser considerada pela crítica uma literatura menor, não temos aqui a intenção de desqualificar as escolhas dos respondentes, pois entendemos, com Chartier (1996, p. 20), que "cada leitor, a partir de suas próprias referências, individuais ou sociais, históricas ou existenciais, dá um sentido mais ou menos singular, mais ou menos partilhado, aos textos de que se apropria”.

Nesse sentido, os comentários dos leitores sobre as literaturas (clássicas e de massa) indiciam que a leitura literária é vista como forma de entretenimento, prazer, consolo, apropriação de conhecimentos, reflexão sobre a existência humana. A nosso ver, essa concepção de leitura literária está ligada à satisfação de seus interesses pessoais, contudo, desqualificar esse modo de ler parece-nos um tanto incoerente, na medida em que esses sujeitos não detêm um conhecimento formal, teórico para lerem essas obras, expressando um posicionamento crítico típico do leitor idealizado por muitos professores. Suas leituras, que se limitam ao seu repertório cultural e às relações subjetivas que estes estabelecem no contato com a obra, nem por isso devem ser desqualificadas, desrespeitadas, pois essas práticas somar-se-ão a outras que serão apropriadas em sua formação acadêmica, ampliando sua biblioteca interior.

À luz dessas considerações, os resultados das análises constataram que as práticas de leitura literária que contribuíram para a formação dos respondentes como leitores foram aquelas em que estes foram tocados pela identificação com o texto. Não por práticas obrigatórias, mas por escolhas livres, sem imposições. Retomando as proposições de Rouxel (2014) e Dalvi (2013), parece-nos que dialogar com os graduandos sobre suas experiências de leitura seja um caminho possível em busca de um alargamento de sua reflexão crítica, construindo novos hábitos de leitura. Concordamos com Souza (2016, p. 216) que "professores que não leem dificilmente conseguem desenvolver este gosto em seus alunos, são eles próprios despossuídos da leitura e reproduzirão isto em sala de aula". É no intuito de insurgir contra essa triste

realidade que os pesquisadores do Projeto PROCAD têm reunido esforços para o desenvolvimento desta pesquisa.

\section{Referências}

BAUMAN, Z. Identidade: entrevista a Benedetto Vecchi. Trad. Carlos Alberto Medeiros. Rio de Janeiro: Jorge Zahar Ed., 2005.

BISCONCIM, L. T. I. Mangá: um estudo de sua forma ficcional e de sua recepção enquanto prática de letramento literário no município de Maringá - Paraná, 2012. 176 f. Dissertação (Mestre em Letras) - Universidade Estadual de Maringá, Maringá, 2012.

BOURDIEU, P. A economia das trocas simbólicas. São Paulo, Perspectiva, 2011. 
BRAVO, R. S. Técnicas de investigação social: Teoria e ejercicios. 7 ed. Ver. Madrid: Paraninfo, 1991.

CARVALHO, M. A leitura dos futuros professores: por uma pedagogia da leitura no ensino superior. Teias: Revista da Faculdade de Educação da UERJ. n. 5 (junho de 2002). Rio de Janeiro: UERJ, Faculdade de Educação, 2001, p. 7-20.

CHAGAS, A. T. S. A ilusão no discurso da auto-ajuda e o sintoma social. Ijuí: Editora UNIJUÍ, 2001.

CHARTIER, R. A aventura do livro: do leitor ao navegador. São Paulo: Ed. da UNESP, 1999.

CHARTIER, R. Práticas da leitura. São Paulo: Estação Liberdade, 1996.

CHARTIER, R. A História Cultural: entre práticas e representações. Tradução Maria Manuela Galhardo. Lisboa: Difel, 1990.

DALVI, M. A.; BATISTA, A. K. C.; PLASTER T. B. Leitura, estudantes de licenciatura e indicadores socioeconômico-culturais: dados preliminares de uma pesquisa. In: Cadernos de Pesquisa em Educação PPGE/CE/Ufes. n. 44. Vitória: PPGE, 2017.

DALVI, M. A. Literatura na escola: Propostas didático-metodológicas. In: DALVI, M. A.; REZENDE , N. L. ; JOVER-FALEIROS, R. (Org.). Leitura de Literatura na Escola. São Paulo, SP: Parábola Editorial, 2013.

HALL, S. A identidade cultural na pós-modernidade. Rio de Janeiro: DP\&A, 2005.

LEWGOY, B. O livro religioso no Brasil recente: uma reflexão sobre as estratégias editoriais de espíritas e evangélicos. Revista Ciencias Sociales y Religión/Ciências Sociais e Religião, Porto Alegre, ano 6, n. 6, p.51-69, outubro de 2004.

LIPOVETSKY, G. A felicidade paradoxal. São Paulo, SP: Companhia das letras, 2010.

LIPOVETSKY, G. A Era do Vazio. Barueri, SP: Manole, 2005.

PAES, J. P. A aventura literária: ensaios sobre ficção e ficções. São Paulo: Companhia das Letras, 1990.

PROJETO de Cooperação Acadêmica Interinstitucional. Leitura nas licenciaturas: espaços, materialidades e contextos na formação docente. Marília, Passo Fundo, Presidente Prudente, Vitória: 2013 (mimeo).

ROUXEL, A. Ensino de literatura: Experiência Estética e formação do leitor. In: ALVES, J. H. P. Memórias da Borborema 4: Discutindo a literatura e seu ensino. Campina Grande: Abralic, 2014.

RUBIM, R.S.S. Leitura Literária de alunos do campus São Mateus do Instituto Federal do Espírito Santo frente ás tecnologias de informação e comunicação contemporâneas. 
2016. 213 f. Dissertação (Mestre em Letras) - Universidade Federal do Espírito Santo, Vitória, 2016.

SODRÉ, M. Best-Seller: a literatura de mercado. Rio de Janeiro: Ática, 1988.

SOUZA, R. F. O habitus do leitor literário: o professor de Língua Portuguesa de Ensino Médio da rede estadual do Espírito Santo. 2016. 273 f. Tese de Doutorado (Doutor em Letras) - Universidade Federal do Espírito Santo, Vitória, 2016.

TODOROV, T. A literatura em perigo. Trad. Caio Meira. $3^{\text {a }}$. Ed. Rio de Janeiro: Difel, 2009.

VALTÃO, R. C. D. Práticas e representações de leitura literária no Ifes/campus de Alegre: uma história com rosto e voz. 2016. 229 f. Dissertação (Mestre em Letras) Universidade Federal do Espírito Santo, Vitória, 2016.

Recebido em: 03/05/2020

Aceito para publicação em: 18/08/2020 